\title{
Public Services Management Efficiency from the Perspective of the Adaptability Degree in the Field of Public Utilities
}

\author{
Tincuta VRABIE GUDANA ${ }^{\star}$, Angela-Eliza MICU ${ }^{\star \star}$
}

\begin{tabular}{l}
\hline \multicolumn{1}{c}{ A R T I C L E I N F O } \\
\hline Article history: \\
Accepted January 2021 \\
Available online April 2021 \\
\hline JEL Classification \\
018, Q15, Q56 \\
Keywords: \\
Waste management, Public sector, \\
Data Envelopment Analysis
\end{tabular}

A B S T R A C T

The present research proposes an analysis of the efficiency of public waste management services, considering the determination of the technical and allocative efficiency of some administrative units in the county of Galați, with responsibilities in this respect. The empirical analysis presupposed the collection of a relevant data set from 2018 in point of: number of households, collection ratio, fee/inhabitant/month, surface and average waste amount generated per year (tons). Considering the analysis at the level of 2018 has the argument the fact that 2018 was the final year when the management of the waste services was the responsibility of the local public administration, as in 2019 the transfer of inventory and competence regarding the waste management service was made from the administrative units to the association of Waste Intercommunity Development Galați. In the present research we resorted to the Data Envelopment Analysis, the CCR model oriented towards input data, as it represents a robust tool for the comparative analysis technique. The results of this analysis are relevant, as it confers municipalities a support to evaluate the efficiency of waste collection programs at the level of each administrative unit under analysis, so that to generate solutions to increase the efficiency of waste collection systems.

(C) 2021 EAI. All rights reserved.

\section{Introduction}

This paper has as a research objective to determine the efficiency of the public utility services, analysed from the perspective of the waste management system. The public utilities services consist of the water supply, sewage and used water purification, thermal energy supply, public lighting, electricity, and last but not least waste management. The waste management service has a great importance due to its compulsory nature, which is why efficiency analysis becomes higher accuracy research. Population increase and industrialization, issues of contemporary society, require the existence of waste management programs, whereby refuse needs to be properly collected and transported to recycling or recuperating units or to the cremation areas. Given that waste originates from various directions and sources, such as: people, farms, production plants, office buildings, households and nature, it is imperative to carefully research the efficiency of waste management and collection. Irrespective of the fact that they are solid or liquid substances, they follow various paths to certain storage locations such as recycling centres, waste storage units, cremation facilities or purification stations.

In the county of Galați, the Association of Waste Intercommunity Development Galați is the association dealing with setting up, organizing, regulating, exploiting, monitoring and administering the waste management service of localities. The members of the Waste Intercommunity Development Galați signed an agreement detailing the manner of project implementation, and the County Council of Galați is the project beneficiary. The members of the council empower the association, through its statutes and articles of association, according to Law no.51/2006 (amended and completed by Governmental Emergency Ordinance no.13/2008) and Government Ordinance no. 855/2008, to perform, on their behalf and responsibility, the attributions, rights and obligations pertaining to them in relation to waste management. Thus, the Waste Intercommunity Development Galați together with the County Council of Galati organize auctions for the waste collection operators. The Waste Intercommunity Development Galați mainly deals with ensuring the improvement of the living standards as a result of replacing and developing the local infrastructure. 


\section{Specialized literature}

The paper's research objective focuses on determining and analysing the efficiency of the public utility services, and more precisely, the public waste management service. The Waste management service serves for meeting the needs of individuals and public institutions in administrative units, as well as protecting and preserving the environment. The waste management system operates through a technological and functional complex, meant to yield the highest degree of efficiency in waste collection and management.

The legal foundation of organizing and operating the public waste management service is the Law no. 51/2006 and Governmental Emergency Ordinance no. 78/2000. Law no.101/2006 stipulates the users of the waste management system whose contracts are managed by the authorities of the local public service, physical or legal persons signing waste management contracts on their own behalf. The law also provides the operators of the waste management service designated by ordinance of administration transfer or decision of contract attribution in the case of delegated inventory. Organizing, operating and administering the waste management service takes place under the conditions of Law no.51/2006 and the law mentioned above. Regarding the regime of refuse, Government Emergency Ordinance no.78/2000 regulates its management in order to protect the environment and the population. Breaking the provisions of these laws attracts the disciplinary, civil, contraventional or criminal liability, as the case may be, and the applicable sanctions.

Considering the complexity and multiple nuances of the given topic, the present research starts by contextualizing the notion of 'public sector'. It is often considered that the public sector is limited in approach at the level of the budget adopted by the political parties in power, but the notion of public sector is much wider and may be defined in various manners by the numerous authors having dealt with this field.

Among these definitions, Lane (2000) states that the public sector means institutions supported by the state budgets and the municipality, whose activity is public-oriented.

Another well-known doctrine founder, Smalskys (2010), defines the public sector as the system of organizations controlling and using the state resources, while Pradhan (1996) claims that the public sector is a combination of public and private elements, stating that public goods and services should be supplied by the private sector by market mechanisms where possible, as this would increase efficiency. Indeed, apart from the cases when it is absolutely necessary, public service supply should be discouraged, given that it may prevent private sector suppliers from becoming more efficient. That is why the approach of public finance tends to favour the solutions of the market and reduce the application area and amplitude of the public sector (Minculete Gh, 2013).

It is still very important to distinguish the notions we use empirically, i.e. efficiency, efficacy, and performance. Efficiency is an indicator obtained by dividing the effects of results to the efforts made, while efficacy is the indicator given by the ratio between the obtained and the forecast result. Drucker (2001) considers that there is no efficiency without efficacy, as it is more important to do well what was proposed, to the detriment of other actions that were not absolutely necessary. Mandl, Dierx and Ilzkovitz (2008) clarified that the analysis of efficiency and efficacy is based on the relation between inputs, results and effects. In regard to the notion of performance, it can be said that this index is closely related to efficiency and efficacy.

According to Profiroiu (2001), performance in the public sector involves a relation between objectives, means and results, so that performance is the result of the simultaneous targeting of efficiency, efficacy and a corresponding budget. In conclusion, the relation between efficiency and efficacy is inclusion, i.e. efficacy is a necessary condition in obtaining efficiency.

Referring to the notion of efficiency in the public sector, Lobonț and Kristmundsson (2016) consider it a result of the resources used, so that it is necessary to consider homogeneous data in the process of sizing and incorporating the idea of production border. According to these authors, the measurement of efficiency requires not only the analysis of resources, but also their quality and orientation, as results can be determined by the political options of the governing bodies as well.

\subsection{Methodological landmarks regarding the efficiency of the public sector}

The degree of knowledge in the field revealed the importance of considering nonparametric research methods, when the objective is sizing performance and/or efficiency in the public sector. Thus, resorting to the methodological tool called Data Envelopment Analysis for the public utility services is no novelty. This tool is also mentioned in the paper by Sanros, Amado and Rosado (2011) who analyse and compare public utility services in point of the efficiency of electricity distribution operators in Portugal, in 2002-2006. The authors used Data Envelopment Analysis oriented towards the input data, in the CRS model. They chose 3 input data as follows: operating costs (euros), network length (kilometres) and transformers capacity (MVAs). For the output data, the authors considered that the number of households where electricity is delivered and the total time of power cuts are relevant data. The study concludes that although some regions in the Iberian Peninsula are efficient, others have difficulty in keeping up with the electricity delivery technology, and the authors suggest that a large part of these difficulties are strictly technical errors of the operators, and not inefficient resource management.

Data Envelopment Analysis was also used in a study by Yüksel (2012). Its objective was the evaluation of the success rate in refuse collection in the biggest 15 Turkish cities. The analysis focuses on the 
output data, in the Charnes Cooper and Rhodes (CCR) model, supplied by the State Institute in Turkey. The input data of the study are the costs of municipalities in refuse management, and city population, and the output data are the refuse collected (tons) and refuse collection (percentiles). The author concludes that the cities of Antalya and Kayseri are the most efficient and for the other cities in the analysis to become efficient it is necessary to increase the refuse collected annually by more than 50 percent.

Last but not least, Lobonț et al. (2017) examine the efficiency of waste management services in 48 administrative units in the Timiș county in 2016. This study is the scientific support of the present research, due to setting the research in Timiș county and the variables that the authors selected as relevant. Also, this study makes use of the methodology called Data Envelopment Analysis, i.e. the Charnes Cooper and Rhodes (CCR) model oriented to the input data. The authors identified 12 administrative units as efficient, and noticed that out of the 12 units, 10 delegated the administrative tasks to the Intercommunity Waste Development Association Timiș, and the two manage refuse on their own, which is unexpected, taking into account that no other locality managing waste on its own is deemed as efficient.

It is to ne remarked that previous studies related to the analysis of the efficiency of public utility services evince both relevant research methodologies, i.e. nonparametric research methodologies, such as Data Envelopment Analysis, i.e. the Charnes Cooper and Rhodes (CCR) model, and the typology of the variables that can be considered as relevant and collected for the intended study. The present paper contributes to developing the specialized literature by proposing a study at the level of Romania, based on developing a new data set, involving administrative units in one of the most representative counties at a regional and territorial level.

\section{Empirical analysis}

\subsection{Methodology and data}

The present paper uses the methodological tool called Data Envelopment Analysis, whose final form was given by Charnes, Cooper and Rhodes (1978), and completed by Banker, Charnes and Cooper (1984). We should also take into account that Farrell (1957) was the first to define a simple measurement of corporate performance by using the numerous inputs in the efficiency unit production. More precisely, Farell expressed the efficiency of unit production by means of the total productivity factor, defined as the ratio between total production and global input. In the study that marks the beginnings of Data Envelopment Analysis, Farrell (1957) was motivated by the need to develop better models and methods for productivity assessment. He claimed that in his attempts to solve the problem careful but overly restrictive measurements were generated, which led to the failure of combining the measurements of multiple entries into a satisfying global measurement. Thus, Farrell (1957) proposed analysing the activity that might adequately solve the problem. In this process, the study performed led to the extension of the concept of productivity to the more general concept of efficiency.

In the study proposed by the present paper, the focus lies on the models in Data Envelopment Analysis in measuring the efficiency of a decision unit related to a similar one, in order to estimate an efficiency border. The results of minute analysis of specialized literature showed that the methodology of Data Envelopment Analysis is an extremely high performance method in efficiency measurements. Moreover, this method develops three main components: $i$ ) it determines efficiency, ii) it determines inefficiency, and iii) it provides efficiency-increasing measures for the units deemed as inefficient.

Efficiency is measured as follows:

$$
E=\frac{\sum u_{j}^{*} y_{j}}{\sum v_{i}^{*} x_{i}} \rightarrow \operatorname{Max}, 0 \leq E \leq 1,
$$

where

$u_{j}$ - weight/importance granted to output $y_{j}$

$y_{j}$-output j, j= $\overline{1, m}$

$v_{i}$ - weight/importance granted to input $x_{i}$

$x_{i}$ - input $\mathrm{i}, \mathrm{i}=\overline{1, n}$

The model called Data Envelopment Analysis used in the present paper is the model devised by Charnes Cooper and Rhodes (CCR) oriented towards input data, aimed at identifying the efficiency-increasing measures from the perspective of the input data, considered at the level of certain variables available at the level of the administrative units. The CCR model is one of the commonest applicative model of the Data Envelopment Analysis (DEA) and the only model that the soft we use can apply, which is one of the limitations of the present research. Moreover, we considered the most relevant input and output variables, in the sense of obtaining conclusive relevant results. 
The data were collected for 2018 by sending written requests to the administrative units of the county of Galați. Considering the analysis at the level of 2019 is based on the argument that 2018 is the last year that the management of the waste disposal fell to the local public service, as in 2019 the transfer of inventory and competence regarding the waste disposal was performed from UAT to the Waste Intercommunity Development Galați. Out of the administrative units contacted, only 20 replied, and only 15 of these could be introduced in the database, providing complete information so that to obtain a homogeneous data set.

The input data variables considered are: (I) fee/inhabitant/month, which is the amount paid by the locals for the waste management service, (II) the coverage degree of the service, which indicates the number of households benefiting from the waste management service reported to the total number of households in the community. Thus, this variable shows the share of the households where refuse is collected. The number of households (III) and surface (IV), this variable being relevant for the length of the refuse collection route. The output variable is the average amount of refuse generated in the locality yearly, expressed in tons.

To sum up, the present empirical analysis refers to the efficiency of the waste management system at the level of 15 administrative units in the county of Galaţi. The selection of the administrative units in the county of Galați took into account the following aspects: the county of Galați is the biggest in the southeastern region of Romania and one of the main economic engines of the country where it is desired to implement a high-performance waste management.

\subsection{Results}

As a result of applying the methodology of the Data Envelopment Analysis by means of the DEASolver Online software, we identified 5 administrative units which are efficient in point of waste management, i.e. Tecuci, Beresti, Tg. Bujor, Matca, Ivesti (figure 1). The other 9 administrative units in our analysis had efficiency scores ranging within 0.08 (8\%) and $0.35(35 \%)$ as shown in Table 1:

Table 1. Efficiency degrees of inefficient administrative units

\begin{tabular}{|c|l|r|}
\hline No. & Administrative units & Efficiency degree \\
\hline 1 & Nicoresti & 0.317652 \\
\hline 2 & Liesti & 0.217860 \\
\hline 3 & Tecuci & 0.634717 \\
\hline 4 & Matca & 0.516059 \\
\hline 5 & Tulucesti & 0.040664 \\
\hline 6 & Smârdan & 0.036377 \\
\hline 7 & Cuca & 0.274876 \\
\hline 8 & Beresti & 0.615073 \\
\hline 9 & Ivesti & 0.389350 \\
\hline 10 & Foltești & 0.120986 \\
\hline 11 & Baleni & 0.080445 \\
\hline 12 & Măstăcani & 0.052335 \\
\hline 13 & Tg. Bujor & 0.510711 \\
\hline 14 & Vânători & 0.354287 \\
\hline 15 & Șendreni & 0.237736 \\
\hline
\end{tabular}

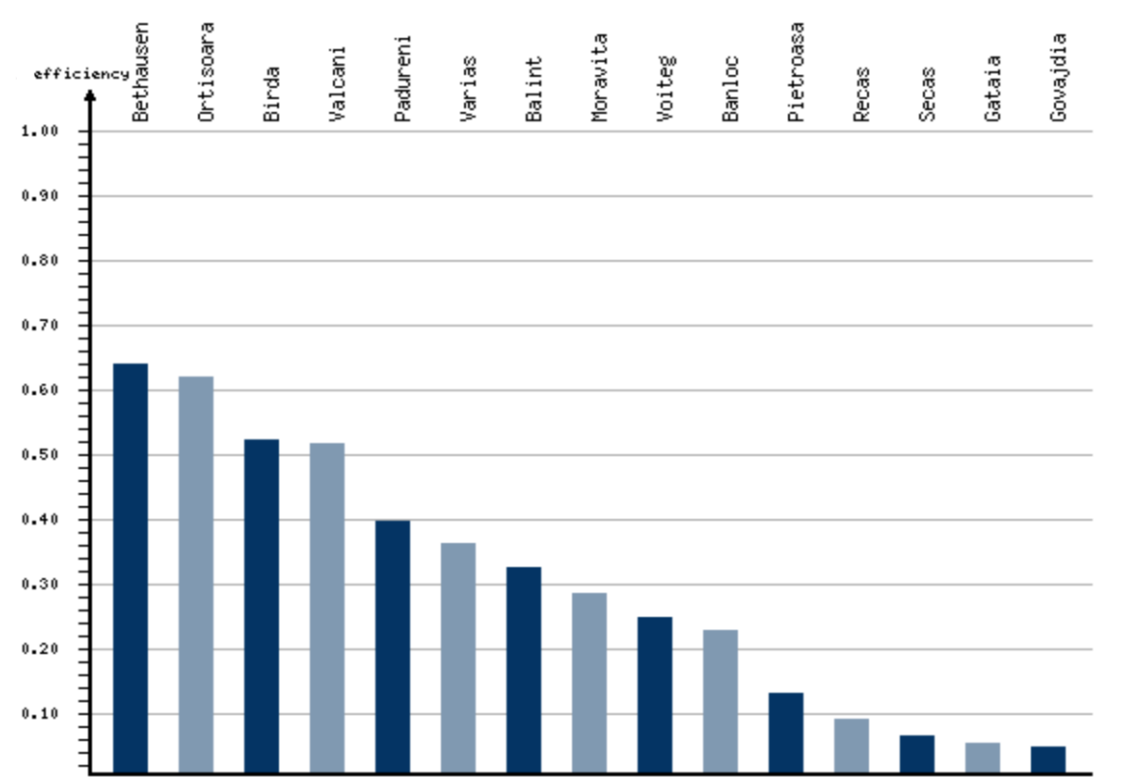

Figure 1. Efficiency degrees of the administrative units seen as inefficient 
The Data Envelopment Analysis provides the following efficiency-increasing measures for the administrative units identified as inefficient (figure 2):

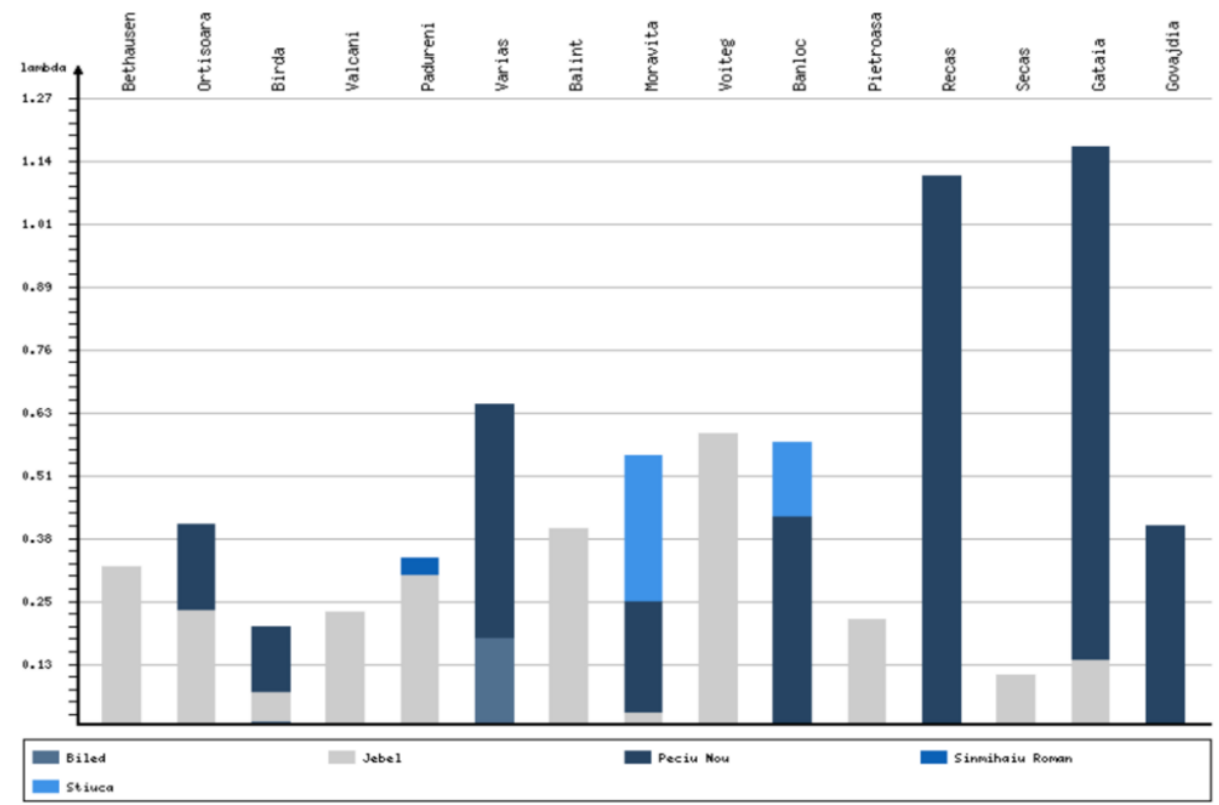

Figure 2. Illustration of efficiency-increasing measures

Although very useful, these efficiency-increasing measures are strictly indicated by relation to the units identified by the methodology as efficient, which is a limitation of the methodology in our opinion. Furthermore, The Data Envelopment Analysis allows for a particular analysis, also considering each input and output variable.

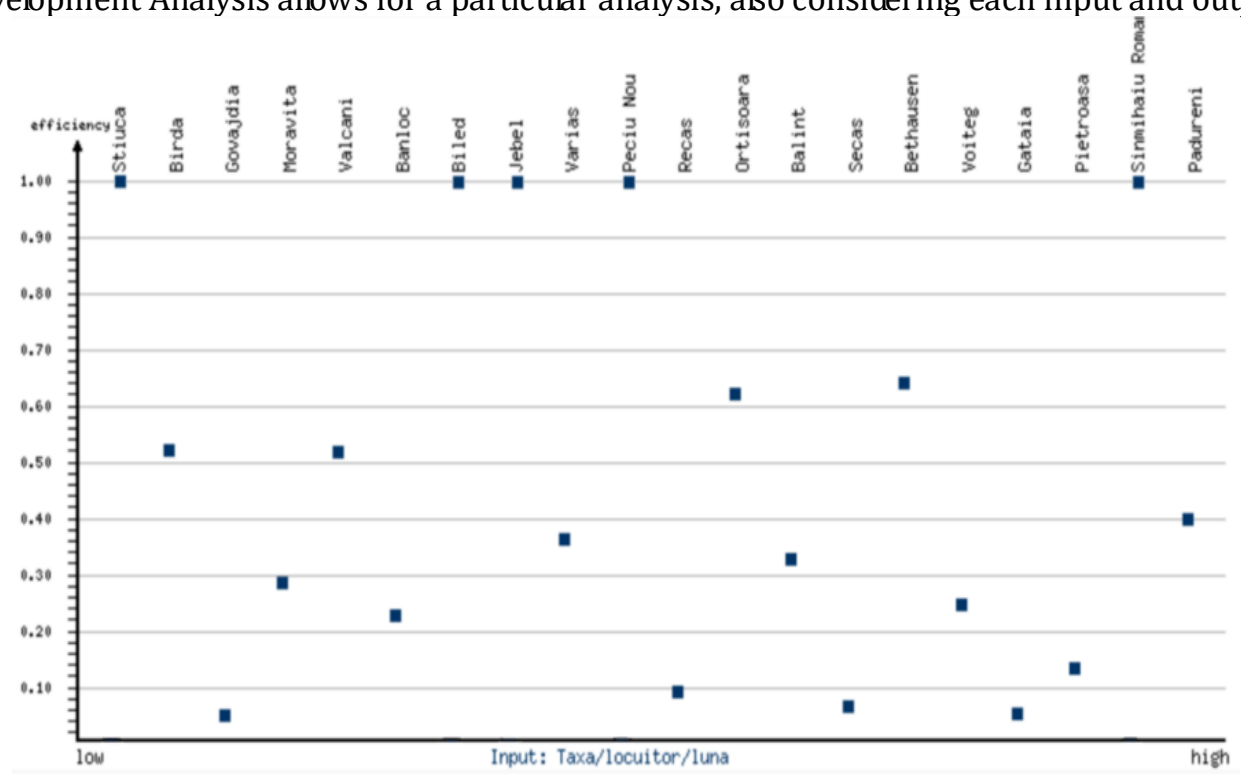

Figure 3. Service efficiency according to the variable fee/inhabitant/month

Figure 3 shows that the amount of the waste management fee has not conditioned efficiency, as Tg. Bujor is an efficient administrative unit and has a higher waste management fee than Liesti or Nicoresti, which are considered as inefficient administrative units. 


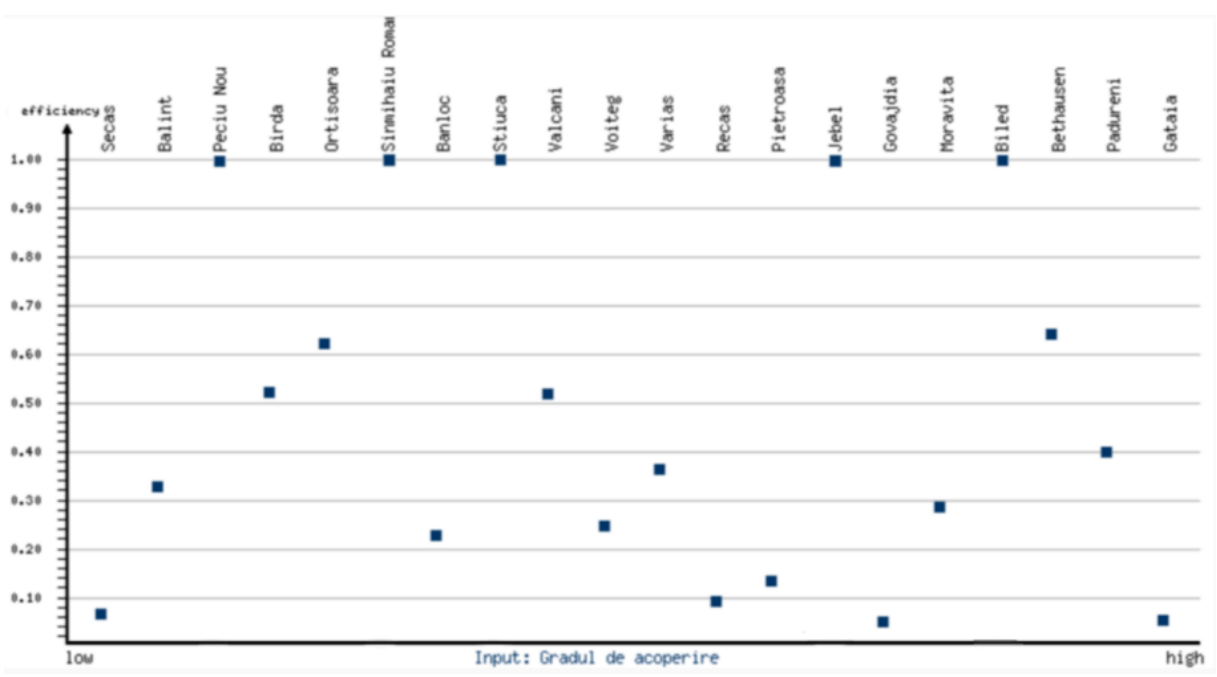

Figure 4. Service efficiency according to the variable service coverage degree

Apart from a few localities, the collection degree is maximum for all the other administrative units. Thus, figure no.4 shows that the coverage degree of the waste management services is an important, but not necessary condition to reach efficiency, as 4 out of the 5 administrative units considered as efficient have a $100 \%$ refuse collection degree (figure 4 ).

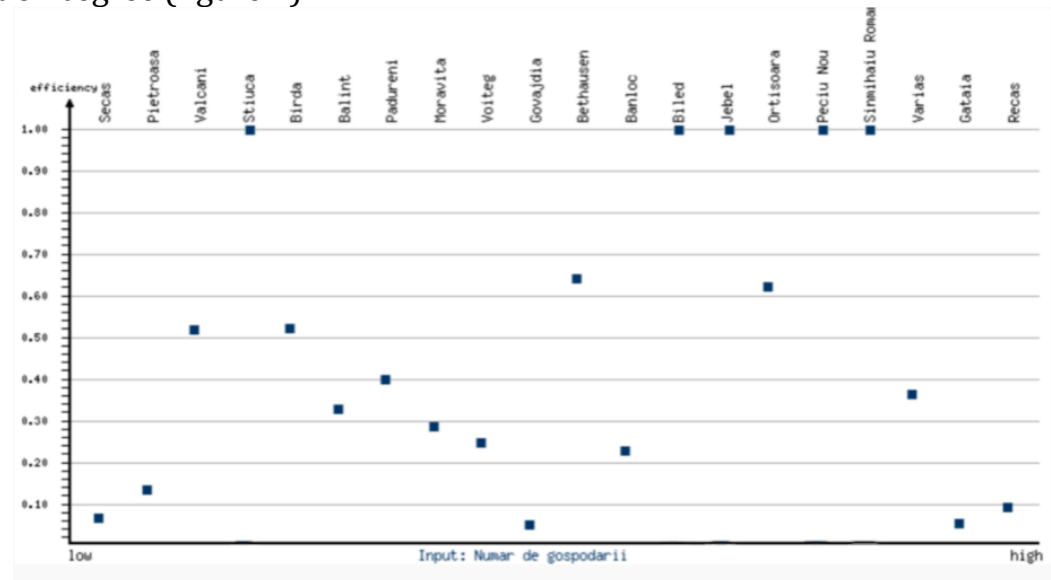

Figure 5. Service efficiency according to the variable number of households

Figure 5 shows that from the point of view of the number of households, the localities Liesti and Nicoresti have the highest efficiency score out of the administrative units considered inefficient, but this does not influence reaching efficiency.

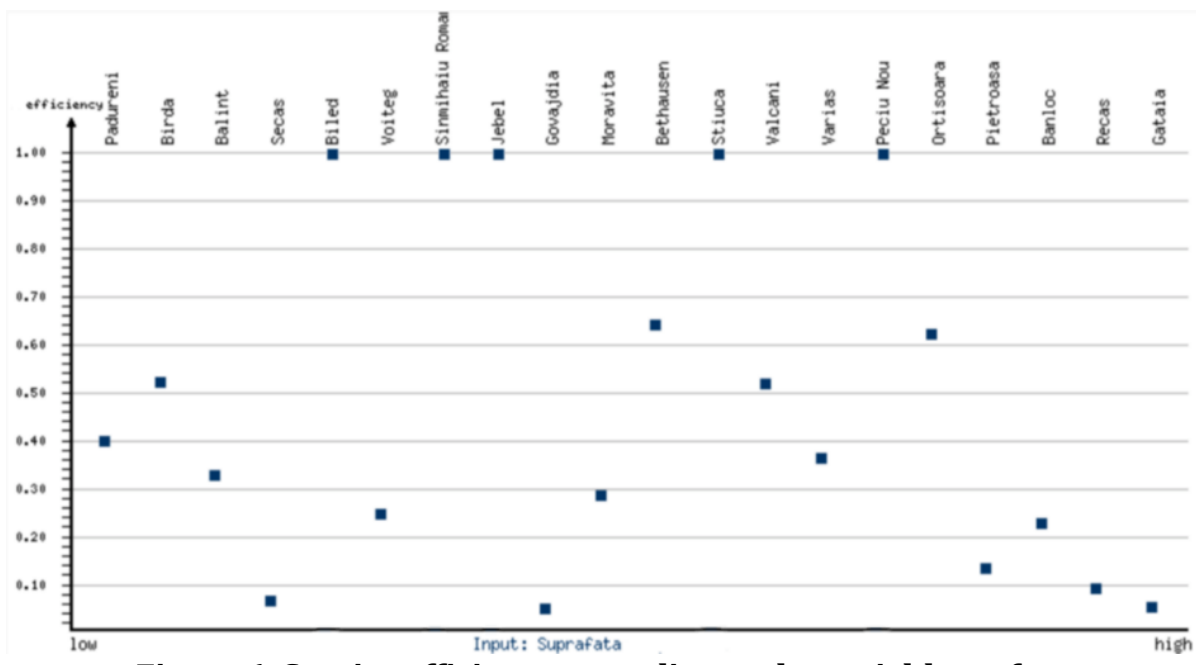

Figure 6. Service efficiency according to the variable surface 
Figure 6 shows in a graphic form the fact that the surface conditioned efficiency, as the locations with a bigger area tend to have a higher efficiency score.

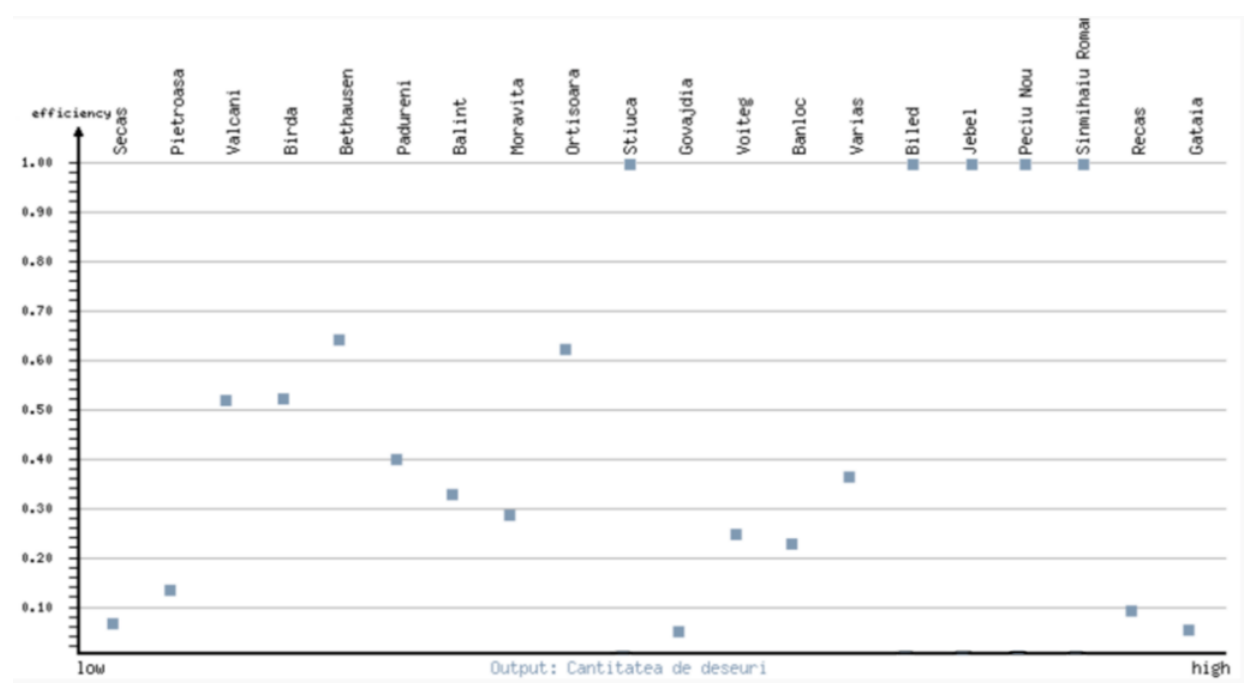

Figure 7. Result expressed according to the variable generated waste amount /year (tons)

Figure 7 shows that the only output variable, i.e. generated waste amount/year was a main requirement to reach efficiency.

In conclusion, it may be observed that the Data Envelopment Analysis proved to be an extremely useful tool in measuring the efficiency of the administration of a public utility service. In our analysis no input or output variables were identified to condition efficiency. The 5 administrative units identified are communities, not towns, and they all delegate waste management to private agents. Although all the 20 administrative units under study rely on the same legislation concerning waste management (Law of waste management service of localities no. 101/2006), the results obtained are not uniform.

\section{Conclusions}

The present paper is the starting point of an investigative process of the public waste management services in the county of Galați, based on the data collected in 2018. The analysis managed to reach the proposed objective by identifying the locations with an efficient system, like: Tecuci, Beresti, Tg. Bujor, Matca, Ivesti and at the same time determining the efficiency percentage of the locations deemed inefficient.

A surprising result on a practical level is that, although the local administrative units considered in our study operate according to the same norms and principles, they obtain different results and performance levels. From a legislative perspective, the field of the community services identified a long process of adaptation and correlation to the European directives and regulations. The county of Galați underwent rapid industrialization and urbanization in the past few decades, which resulted in changes of the features of waste management, taking into account that it was in 2019 that the waste management service inventory and competence was transferred from the administrative units to the association of Waste Intercommunity Development Galați.

The main aspect to be focused upon in the creation of a sustainable waste management system is the availability of information on the characteristics of the waste produced. An adequate training is essential regarding allotting sufficient funds to manage waste, and ecological awareness and education should not be ignored, together with continuous awareness campaigns and programs.

\section{References:}

1. Banker, R.D., Charnes, A., and Cooper W.W., (1984). Some Models for Estimating Technical and Scale Inefficiencies in Data Envelopment Analysis, Management Science, vol.30, p. 659-663

2. Charnes, A., Cooper, W.W., Rhodes, E., (1978). Measuring the efficiency of decision making unit, European Journal of Operational Research, vol. 2, p. 429-444

3. Drucker, P., (2001). The ecological vision: Reflections on the American condition, Routledge p. 147.

4. Farrell, M.J., (1957). The Measurement of Productive Efficiency, American Journal of Industrial and Business Management, vol.7

5. Yüksel, H., (2012). Evaluating the Success of Waste Collection Programs of Municipalities with Data Envelopment Analysis, International Journal of Environmental Protection

6. Lane, J.E., (2000). The public sector: concepts, models and approaches, Sage, nr.3

7. Lobont, O, Kristmundsson O., (2016). Public Sector Governance, Ed. Mirton, p.70-75

8. Lobonț, O., Bociu A., Olariu D.B., Para I., (2017). Efficiency of sanitation service provision, a key for strategic development of public administration: the case of Romania, conference presentation.

9. Minculete, G. (2013, May). Issues regarding electronic commerce and e-marketing. In International Scientific Conference" Strategies XXI" (Vol. 2, p. 26). " Carol I" National Defence University. 
10. Pradhan S., (1997). Evaluating Public Spending: A Framework for Public Expenditure Reviews, 1World Bank Discussion Paper (Book 323)

11. Profiroiu, M., (2001). Cadrul de analiză a performanțelor sectorului public, Romanian Journal of Economic Forecasting, p.8.

12. Smalskys, V., (2010). Public administration, Baltic Journal of Law \& Politics, vol.3

13. Sanros, S.P., Amado, C. and Rosado, J.R., (2011). Formative evaluation of electricity distribution utilities using Data Envelopment Analysis, Journal of the Operational Research Society

14. Ulrike, M., Dierx, A., and Ilzkovitz, F., (2008). The effectiveness and efficiency of public spending, Economic papers, $p .301$

15. http://www.dea.fernuni-hagen.de 